Department of Community Medicine, Medical School, Ahwaz University of Medical Sciences, Ahwaz, Iran H Soori

Ministry of Health of Iran, Tehran, Iran M Naghavi

Correspondence to: Dr Soori.

\title{
Childhood deaths from unintentional injuries in rural areas of Iran
}

\author{
Hamid Soori, Mohsen Naghavi
}

\begin{abstract}
Objectives-To determine the incidence of children's fatal unintentional injuries in rural areas of Iran.

Setting-Thirteen provinces of Iran, with a total population of 11.3 million for 1993-94. Methods-A descriptive epidemiological study, which obtained information about all deaths using a questionnaire from 6267 Health Houses (rural health centres) for one year, 1993-94. Subjects were residents who died from unintentional injuries.

Results-Crude mortality rate was 4.33 per 1000. The number of childhood deaths from unintentional injuries was 1832 (16.6\% of all deaths), more among males than females $(43.7 v 31.2$ per 100000$)$. Those under 1 had the highest rate, 114.7 per 100000 . The top three causes of deaths were traffic accidents $(37.5 \%)$, drowning (17.9\%), and burns and scalds (12.1\%).

Conclusions-During the past decade there has been a marked decline in deaths from infectious diseases in Iran. However, at present, a high proportion of childhood deaths in rural areas are from unintentional injuries. Because all age groups and both sexes are victims of unintentional injuries, and most injuries are preventable, they must be considered as a priority health problem in Iran.

(Injury Prevention 1998;4:222-224)
\end{abstract}

Keywords: unintentional injuries; gender; rural areas; Iran

Accidental injuries are the commonest cause of death and hospital admission, and can result in lifelong disability. ${ }^{1}$ They are a threat to health in every country, are currently responsible for $7 \%$ of world mortality, and this proportion is predicted to rise.

It is wrongly believed by some that accidents are problems of developed countries or of urban areas. In developing countries (and also in rural areas), they are perhaps just as common, and their consequences are often more serious. ${ }^{2}$ Strategies for injury prevention have been extensively studied in many developed nations but not in the developing world. According to a national report on vital statistics in Iran, after chronic heart diseases, injuries are the commonest cause of deaths in different age groups. ${ }^{3}$
Due to a lack of organisation and funding, the data capture systems in Iran are inadequate. In rural areas of Iran, data on deaths are mainly collected in Health Houses. They are the rural health centres and staffed by one or two trained native health workers. Their main function is to offer primary health care services to rural areas of Iran. Some of their responsibilities are educating the public about health matters, providing simple treatments and family planning services, monitoring children for growth and development, environmental health activities, and recording health information. However, their activities exclude injury control and prevention and their data exclude details about deaths from unintentional injuries.

The distribution of injuries among different ages and between the sexes vary by cause and type. ${ }^{45}$ There are also some studies about injuries in rural areas of different parts of the world. ${ }^{4-8}$ However, no previous study in Iran has attempted a comprehensive regional analysis of accidental deaths. In this study an epidemiological description of deaths from unintentional injuries is presented.

\section{Methods}

This cross sectional study collected information from 6267 Health Houses in 13 provinces in Iran. For inclusion the injury had to be unintentional and led to death between 21 March 1993 to 20 March 1994 (21 March is the first day of the year in the Persian calendar).

A checklist questionnaire was sent to 6267 Health Houses asking about cause of death, age, sex, place of residence of victims, and also a brief description of the accident. An instructional sheet was attached to the questionnaires which the health workers were asked to read carefully. Each Health House serves 10001500 inhabitants. Since the health workers were chosen from the main village they have an intimate relationship with the village in which the Health House is stationed. They record all deaths that occur in their area.

The definitions of external causes of injury and poisoning used in this study followed the International Classification of Diseases (E800E999). All analyses were conducted using EpiInfo (version 6.0). In statistical analyses 95\% confidence intervals (CI) for the difference between proportions were employed where appropriate. 
Table 1 Total population, number of all deaths, and number of deaths from unintentional injuries by age group and sex

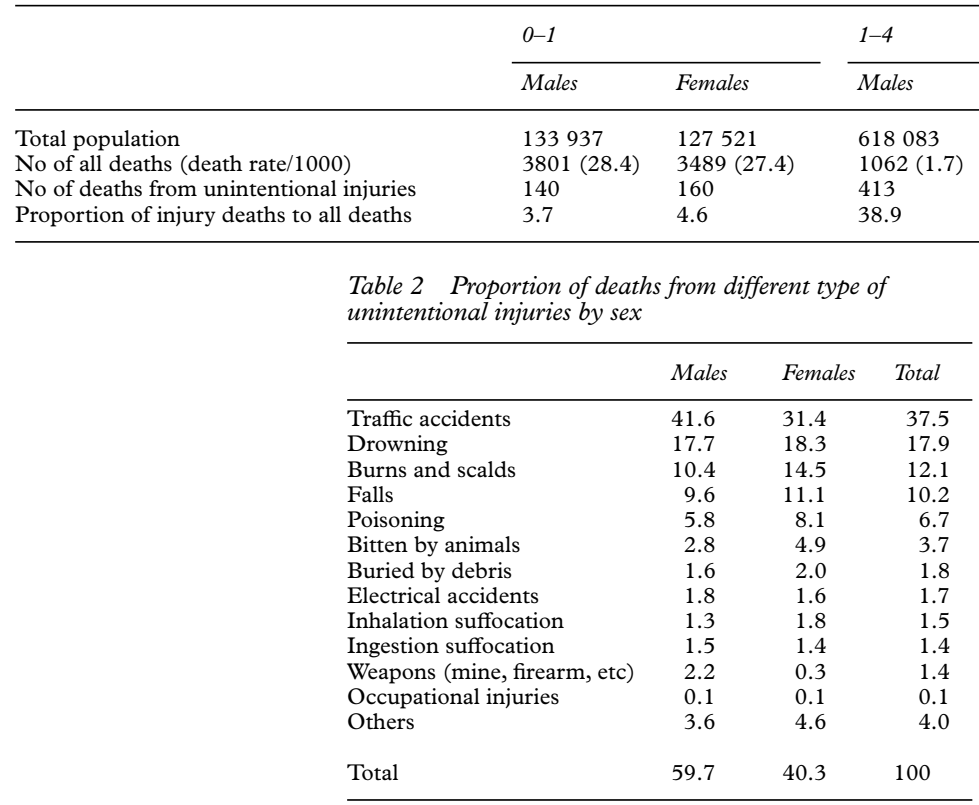

\section{Results}

Table 1 shows total population, number of all deaths, and number of deaths from unintentional injuries by age group and sex. Males aged $5-14$ had the highest proportion of deaths from unintentional injuries, $51.6 \%$ (95\% CI $0.02 \%$ to $0.03 \%$ ) of all deaths.

Table 2 shows proportion of deaths from different types of unintentional injuries by sex. The top three causes of deaths resulted from unintentional injuries were traffic accidents $(37.5 \%)$, drowning $(17.9 \%)$, and burns and scalds $(12.1 \%)$. For all type of accidental deaths, $59.7 \%$ occurred in males and $40.3 \%$ in females (95\% CI $0.16 \%$ to $0.23 \%$ ). Compared with other causes of accidental deaths, traffic accidents were the most important cause of accidental deaths $(37.5 \%, 95 \%$ CI 0.35 to $0.40)$. There was also a marked higher proportion of accidental deaths from traffic accidents $(41.6 \%$ v $31.4 \%, 95 \%$ CI 0.06 to $0.15)$ and weapons $(2.2 \%$ v $0.3 \%, 95 \%$ CI 0.01 to 0.03 ) in males compared with females. However, there was a higher proportion of accidental deaths from burns and scalds $(14.5 \%$ v $10.4 \%, 95 \%$ CI 0.01 to 0.07$)$ and being bitten by animals $(4.9 \%$ v $2.8 \%, 95 \%$ CI 0.01 to 0.04 ) in females compared with males.

Table 3 shows number of deaths from different type of unintentional injuries by age group and sex. Most deaths from unintentional injuries were from traffic accidents with 455 for males and 232 for females.

Table 4 shows mortality rate per 100000 for unintentional injuries by age group and sex. Mortality rate for unintentional injuries for all age groups was 37.6 per 100000 . Except for those under 1 year, males of other age groups had a higher mortality rate for injuries than females. Of all deaths from unintentional injuries $30.0 \%$ occurred in summer, $26.0 \%$ in spring, $24.0 \%$ in autumn, and $20.0 \%$ in winter.

\section{Discussion}

This study showed that many children in rural areas of Iran die of unintentional injuries. Males had a higher rate than females, and traffic accidents, drowning, and burns and scalds were the most important causes of deaths.

This study was the first on unintentional deaths in rural areas of Iran carried out for a large population. Because of health workers' cooperation we obtained a $100 \%$ response rate. There were some limitations in this study. Lack of detailed information made it impossible to present complete data about place and time of deaths or more details about the victims.

This study showed age and sex differences that have been shown in some other studies. $^{2910}$ To our knowledge there is no directly comparable Iranian study. However, there is some research on injuries in rural areas. In the United States, Grossman et al showed that $58 \%$ of their subjects were injured in rural areas. ${ }^{11}$ Van and Shackford showed that in victims less than 19 years old, injury mortality was higher than in urban areas. ${ }^{12}$ Alexander et al, in a study on behavioral risk factors for injury

Table 3 Number of deaths from different type of unintentional injuries by age group and sex

\begin{tabular}{|c|c|c|c|c|c|c|c|c|}
\hline & \multicolumn{2}{|l|}{$0-1$} & \multicolumn{2}{|l|}{$1-4$} & \multicolumn{2}{|l|}{$5-14$} & \multicolumn{2}{|l|}{ Total } \\
\hline & Males & Females & Males & Females & Males & Females & Males & Females \\
\hline Traffic accidents & 19 & 15 & 141 & 90 & 295 & 127 & 455 & 232 \\
\hline Drowning & 7 & 16 & 101 & 87 & 85 & 32 & 193 & 135 \\
\hline Burns and scalds & 17 & 19 & 68 & 59 & 29 & 29 & 114 & 107 \\
\hline Falls & 31 & 31 & 35 & 35 & 39 & 16 & 105 & 82 \\
\hline Poisoning & 32 & 35 & 26 & 18 & 5 & 7 & 63 & 60 \\
\hline Bitten by animals & 6 & 8 & 9 & 15 & 16 & 13 & 31 & 36 \\
\hline Buried by debris & 0 & 2 & 6 & 4 & 12 & 9 & 18 & 15 \\
\hline Electrical accidents & 0 & 3 & 6 & 7 & 14 & 2 & 20 & 12 \\
\hline Inhalation suffocation & 6 & 11 & 5 & 1 & 3 & 1 & 14 & 13 \\
\hline Ingestion suffocation & 8 & 6 & 7 & 4 & 1 & 0 & 16 & 10 \\
\hline Weapons (mine, firearm, etc) & 0 & 0 & 3 & 0 & 21 & 2 & 24 & 2 \\
\hline Occupational injuries & 0 & 0 & 0 & 0 & 1 & 1 & 1 & 1 \\
\hline Others & 14 & 14 & 6 & 10 & 19 & 10 & 39 & 34 \\
\hline Total & 140 & 160 & 413 & 330 & 540 & 249 & $1093(59.7 \%)$ & $739(40.3 \%)$ \\
\hline
\end{tabular}


Table 4 Mortality rate per 100 000 for unintentional injuries by age group and sex

\begin{tabular}{|c|c|c|c|c|c|c|c|c|}
\hline & \multicolumn{2}{|l|}{$0-1$} & \multicolumn{2}{|l|}{$1-4$} & \multicolumn{2}{|l|}{$5-14$} & \multicolumn{2}{|l|}{ Total } \\
\hline & Males & Females & Males & Females & Males & Females & Males & Females \\
\hline \multirow[b]{2}{*}{ Total } & 104.5 & 125.5 & 66.8 & 55.8 & 30.9 & 15.1 & 43.7 & 31.2 \\
\hline & \multicolumn{2}{|c|}{114.7} & \multicolumn{2}{|c|}{61.4} & \multicolumn{2}{|c|}{23.2} & \multicolumn{2}{|c|}{37.6} \\
\hline
\end{tabular}

among rural adolescents, reported that more than half $(53.5 \%)$ of those aged $12-14$ reported having experienced one or more injuries with sex and race differences, a high degree of risk taking, and low parental supervision.?

In Denmark, Jorgensen, ${ }^{13}$ in a study on children aged 0-14 who died from unintentional injuries, showed that for boys the risk of unintentional injury death was $32-48 \%$ greater, and for girls the risk was $40 \%$ higher, in rural areas than in Denmark as a whole.

Our results reinforced the importance of unintentional injuries as a major cause of deaths in rural areas. Berger and Mohan explained that the major type of injuries in developing countries are traffic accidents, falls, drowning, and poisoning. ${ }^{14}$ However, the nature and extent of injuries vary according to urban or rural areas. In our study, the main causes of accidental deaths were very similar to Berger and Mohan's findings.

Forjuoh states that "developing countries are now hanging between the stages of epidemiologic polarization and protracted epidemiologic transition". ${ }^{15}$ Iran has achieved good results in reducing morbidity and mortality from infectious diseases by 15 years of dedicated effort. ${ }^{16}$ However, the importance of unintentional injuries as one of the major causes of death is undeniable, and the science of injury control should be a national task. In Iran, like many other developing countries, developments in motorization and industrialization occurred much faster than in industrialized countries, without the accompanying other improvements, and it may increase the number of accidental deaths.
About 30 years ago, the European Office of the World Health Organisation suggested that countries should have a central institution, governmental or non-governmental, designated for child safety. ${ }^{17}$ There is no injury organisation, funding, or data capture system in Iran at present. Injury related policies must be considered as a priority health problem in this country, and a well organised system established for childhood accident prevention. International support as well as national efforts may enhance the chances of prevention and control of these injuries in Iran. 1 Department of Health. The health of the nation. Key area Manciaux M, Romer C. Accidents in childhood and Manciaux M, Romer C. Accidents in childhood and
adolescence. The role of research. Geneva: World Health adolescence. The role
Organisation, 1991 .

3 Malek-Afzali H, Mahmoudi M. A review on vital statistics in Iran. Daru Va Darman 1993:5-12.

4 Alexander CS, Somerfield MR, Ensminger ME, et al. Gender differences in injuries among rural youth. Inj Prev 1995;1:15-20.

5 Wilson M, Baker S, Teret S, et al. Saving children. A guide to injury prevention. New York: Oxford University Press, 1991.

6 Trankle U, Gelau C, Metker T. Risk perception and age-specific accidents of young drivers. Accid Anal Prev 1990;22:119-25.

7 Alexander CS, Ensminger ME, Somerfield MR, et al. Behavioral risk factors for injury among rural adolescents. Am f Epidemiol 1992;136:673-85.

8 Jansson B, Eriksson C. Accident involvement and attitude Jansson B, Eriksson C. Accident involvement and attitude
towards hazards and countermeasures in a Swedish rural towards hazards and countermeasures in a Sw
population. Scand $\mathcal{F}$ Soc Med 1990;18:139-42.

9 Joly $M$, Foggin P, Pless I. Geographical and socioechological variations of traffic accidents among children. Soc Sci Med 1991;33:765-9.

10 Avery J, Jackson R. Children and their accidents. London: Edward Arnold, 1993.

11 Grossman D, Kim A, Macdonald S, et al. Urban-rural differences in prehospital care of major trauma. 7 Trauma 1997;42:723-9.

12 Van D, Shackford S. Epidemiology of rural traumatic death in children: a population-based study. F Trauma 1995;38: 867-70.

13 Jorgensen I. Fatal unintentional child injuries in Denmark. Dan Med Bull 1996;43:92-6.

14 Berger L, Mohan D. Injury control-a global view. Delhi: Berger L, Mohan D. Injury contro
Oxford University Press, 1996.

15 Forjuoh SN. Injury control in developing nations: what can we learn from industrialized countries? Inj Prev 1996;2:90-1. 16 Shadpour K. The PHC experience in Iran. Tehran: Unicef, 1994.

17 European Public Health Committee. Accidents in childhood as a public health problem. Strasbourg: Council of Europe, 1972 .

\section{Sayonara journal citations}

Studious readers may note that in neither this issue nor the last has the section entitled "Journal citations" appeared. The decision to abandon this feature was made with some misgivings (and some relief) after consultation with the editorial board. Other such changes, reflecting our determination to ensure that Injury Prevention is as useful and appealing as possible, may follow.

The journal citations represented a great deal of work for me personally and for Sue Heels, our technical editor. Several of the board noted that there did not appear to be many who made use of it. Moreover, we reasoned that perhaps most readers who need this information can obtain it themselves by searching the internet.

To assist those who wish to do so, I offer the following guidelines: first I searched MEDLINE, Current Contents, PsychoInfo, and Education. (If EMBASE were available I would have included it as well as several other, more specialized databases-for example in engineering, transport, and urban planning.) Second, I used a simple search strategy: (child\$ or adoles\$) AND (accident\$ or injur\$) AND (prevention) and limited the result to the current year. Finally, this file was downloaded and entered into Reference Manager where the results were compared with what was already in the database to avoid duplication.

If enough readers request it, I will consider doing this search once a year and publishing the results. But for the present we are saying farewell, sayonara, and perhaps au revoir to the journal citations. I welcome your comments.

EDITOR 